\title{
Development and comparison of loop-mediated isothermal amplification and quantitative polymerase chain reaction assays for the detection of Mycoplasma bovis in milk
}

\author{
Sandra Appelt, ${ }^{1}$ Sharif S. Aly, ${ }^{2,3}$ Karen Tonooka, ${ }^{2}$ Kathy Glenn, ${ }^{2}$ Zhengyao Xue, ${ }^{1}$ Terry W. Lehenbauer, ${ }^{2,3}$ \\ and Maria L. Marco $0^{1,2 *}$ \\ ${ }^{1}$ Department of Food Science and Technology, University of California, Davis 95616 \\ ${ }^{2}$ Veterinary Medicine Teaching and Research Center, School of Veterinary Medicine, University of California Davis, Tulare 93274 \\ ${ }^{3}$ Department of Population Health and Reproduction, School of Veterinary Medicine, University of California, Davis 95616
}

\section{ABSTRACT}

Bovine mastitis is an economic burden for dairies worldwide. Mycoplasma species, and especially Mycoplasma bovis, are among the most important causative agents, and rapid, precise, and low-cost methods for Mycoplasma detection are urgently needed. For this purpose, loop-mediated isothermal amplification (LAMP) and quantitative PCR (qPCR) assays were developed and compared. The LAMP assay was designed and primer concentrations optimized to $M$. bovis oppD, encoding oligopeptide permease D. For qPCR, a Taqman assay (Applied Biosystems, Carlsbad, CA) targeting $M$. bovis glt $X$, encoding glutamate transfer RNA ligase, was optimized for primer concentration, annealing temperature, and DNA polymerase. Both assays were similarly sensitive, with a detection limit of approximately $10^{4}$ to $10^{5}$ M. bovis cells $/ \mathrm{mL}$. Both assays were also successful in confirming $M$. bovis identity in laboratory culture suspensions and in bovine milk. The LAMP and qPCR assays combined with the MoBio DNA extraction kit (MoBio Laboratories Inc., Carlsbad, CA) resulted in the correct detection of 13 out of $13 \mathrm{M}$. bovis isolates and 14 out of $16 \mathrm{M}$. bovis-positive milk samples collected from commercial dairies in California. When combined with the PrepMan Ultra reagent (Applied Biosystems), the qPCR assay resulted in confirming 21 out of $21 \mathrm{M}$. bovis-positive milk samples. Comparison of the assays to milk containing either Mycoplasma arginini, Mycoplasma bovigenitalium, Mycoplasma californicum, M. alkalescens, or Acholeplasma laidlawii or milk lacking any detectable Mycoplasma species or relatives resulted in 3 out of 17 (LAMP with MoBio), 1 out of 17 (qPCR with MoBio), and 2 out of 36 (qPCR with

Received June 29, 2018.

Accepted November 5, 2018.

*Corresponding author: mmarco@ucdavis.edu
PrepMan Ultra) false positives. Overall, the qPCR assay was more robust than LAMP and could be used on DNA recovered from milk prepared with the PrepMan Ultra reagent, a method that does not include a DNA purification step. The use of this qPCR method enables M. bovis detection in bovine milk in 40 to $55 \mathrm{~min}$, and therefore provides new opportunities to accelerate and simplify $M$. bovis detection in unpasteurized milk to reduce the incidence of $M$. bovis mastitis outbreaks.

Key words: mastitis, Mycoplasma, milk, molecular detection

\section{INTRODUCTION}

Inflammation of the udder, also known as mastitis, is the most prevalent disease on commercial dairies and is a significant economic burden to the dairy industry worldwide (Halasa et al., 2007; Bar et al., 2008). Of the numerous recognized mastitis pathogens, Mycoplasma bovis, Staphylococcus aureus, and Streptococcus agalactiae are contagiously transmitted during milking and may cause subclinical or clinical chronic mastitis (Bayoumi et al., 1988; Fox and Gay, 1993; Bar-Gal et al., 2015).

Among these pathogens, species of Mycoplasma are of greatest concern because they are resistant to $\beta$-lactam antibiotics and are consequently difficult to treat (Jasper, 1977; Caswell and Archambault, 2007; Fox, 2012). Mycoplasma bovis is the most common Mycoplasma species associated with bovine mastitis, although numerous other species, including Mycoplasma californicum, Mycoplasma alkalescens, and Mycoplasma bovigenitalium, are also known to cause this disease (Jasper, 1977; Jasper et al., 1979; González et al., 1988; Kirk et al., 1997; Fox, 2012). Mycoplasma have been isolated from mastitic cattle worldwide (Fox et al., 2005). In the United States, the prevalence of Mycoplasma is estimated at $14.4 \%$ in larger herds (500 or more cows), $4.2 \%$ in medium herds (100 to 499 cows), 
and $1.8 \%$ in herds smaller than 100 cows (González et al., 1988; Kirk et al., 1997; USDA, 2008). Mycoplasma spp. have a higher prevalence in the western states in the United States, as compared with the eastern states, and in larger herds (500 or more cows; USDA, 2008).

To prevent the further spread of $M$. bovis in dairy herds, rapid, precise, and low-cost methods for detection are urgently needed. We estimated that testing for Mycoplasma spp. according to laboratory culture-based methods requires at least $7 \mathrm{~d}$ and costs approximately $\$ 6$ per milk sample (Murai et al., 2014). Species identification in private milk quality laboratories is commonly based on the assessment of colony morphology using selective media and requires specialized training to distinguish between phenotypically similar colonies. This approach renders identification challenging and sometimes even impossible. Such methods have long been regarded as the gold standard for Mycoplasma detection (Baas and Jasper, 1972; Parker et al., 2018); however, it is not possible to distinguish between different Mycoplasma species by colony morphology alone, and other non-pathogenic milk contaminants such as Acholeplasma species can be falsely identified as $M y$ coplasma. To address this shortcoming, immunofluorescence-based techniques have been used for species verification of single colony isolates (Baas and Jasper, 1972). The use of immunofluorescence is laborious, costly, difficult to perform, and the necessary reagents are not widely available. Overall, the use of laboratory culture to detect $M$. bovis is very time-consuming, expensive, and labor-intensive.

Previous research has developed DNA-based, loopmediated isothermal amplification (LAMP; Bai et al., 2011; Higa et al., 2016; Ashraf et al., 2018) and quantitative (q) PCR (Cai et al., 2005; Clothier et al., 2010; Rossetti et al., 2010; Sachse et al., 2010; Boonyayatra et al., 2012; Naikare et al., 2015; Gioia et al., 2016; Parker et al., 2017; Behera et al., 2018) assays to detect Mycoplasma. The LAMP is of interest because it does not require expensive laboratory equipment (Notomi et al., 2000; Li et al., 2017). Quantitative PCR assays have advantages over conventional PCR methods because qPCR enables more sensitive and precise detection of multiple strains or species as well as the enumeration of total cell numbers (Naikare et al., 2015; Kralik and Ricchi, 2017). Although both LAMP and qPCR were shown to be applicable for the accurate detection of $M$. bovis and other Mycoplasma species in milk (Clothier et al., 2010; Rossetti et al., 2010; Naikare et al., 2015; Parker et al., 2017; Ashraf et al., 2018; Behera et al., 2018), direct comparisons of LAMP and qPCR methods are lacking, as are efforts to optimize the assays to accelerate and simplify detection.
The objective of our study was to develop molecular detection methods for $M$. bovis in raw milk that are accurate, low-cost, and with known detection limits. For this purpose, we designed real-time PCR and LAMP assays and tested them on Mycoplasma isolates and milk samples positive or negative for $M$. bovis according to standard laboratory approaches.

\section{MATERIALS AND METHODS}

\section{Milk Samples and Bacterial Isolates}

A total of 68 milk samples were collected from 9 individual cow mastitic quarters $(\mathrm{n}=9)$ and bulk tanks from 59 dairies $(\mathrm{n}=59)$ in the Central Valley of California and received by the University of California, Davis, Veterinary Medicine Teaching \& Research Center (VMTRC), Milk Quality Laboratory (Tulare, CA). A fraction of each of these milk samples was preserved by freezing at $-20^{\circ} \mathrm{C}$ and the remaining fraction was analyzed for Mycoplasma using VMTRC Milk Quality Laboratory culture protocols adapted from the National Mastitis Council (NMC, 2017). For Mycoplasma species identification, an established fluorescent staining procedure was used (Baas and Jasper, 1972). Species identity was also confirmed by $16 \mathrm{~S}$ rRNA gene sequencing as previously described (Lane, 1991). Based on these assessments, the milk samples were either negative for Mycoplasma (15 samples) or contained $M$. bovis (23 samples), M. bovigenitalium (13 samples), $M$. californicum (8 samples), M. alkalescens (5 samples), Mycoplasma arginini (2 samples), or Acholeplasma laidlawii (2 samples; Supplemental Table S1, https://doi .org/10.3168/jds.2018-15306). Additionally, genomic DNA (gDNA) from $M$. bovis type strain Donetta PG45 ATCC 25523 (Hale et al., 1962; Wise et al., 2011) was purchased from the American Type Culture Collection (ATCC, Manassas, VA).

The milk samples and the bacterial isolates enriched from those samples were examined in various ways. A total of 21 of the bacterial isolates were selected for direct examination by the LAMP and qPCR assays developed here (Supplemental Table S1; https://doi.org/ 10.3168/jds.2018-15306). The milk samples were also distributed for LAMP and qPCR testing with different DNA extraction methods (Supplemental Table S1).

\section{Preparation of Heat-Killed Mycoplasma Isolates}

For molecular analysis to be performed in the Marco laboratory (Department of Food Science and Technology, University of California, Davis), Mycoplasma isolates were grown at the VMTRC Milk Quality 
Laboratory in Modified Hayflick agar medium (Veterinary Medicine Biological Media Services, UC Davis, Davis, $\mathrm{CA}$ ) and incubated at $37^{\circ} \mathrm{C}$ in $5 \% \mathrm{CO}_{2}$ for $3 \mathrm{~d}$. To facilitate transport between the Tulare and Davis laboratories, the bacterial cells were next collected by centrifugation at $13,800 \times g$ for $5 \mathrm{~min}$ at $21^{\circ} \mathrm{C}$, suspended in $2 \mathrm{~mL}$ of $\mathrm{PBS}$, and then incubated for $30 \mathrm{~min}$ at $60^{\circ} \mathrm{C}$. Heat-inactivation was confirmed by plating 50 $\mu \mathrm{L}$ of the cell suspension onto modified Hayflick agar and incubating at $37^{\circ} \mathrm{C}$ for $7 \mathrm{~d}$. Samples were held at $-20^{\circ} \mathrm{C}$ until confirming that the Mycoplasma cells were inactivated and then shipped to the Marco laboratory at the Davis campus for further testing. These samples were used directly for LAMP and qPCR assays because DNA extraction and purification steps were deemed to be unnecessary.

\section{Genomic DNA Extraction}

Cells in $2 \mathrm{~mL}$ of milk were collected by centrifugation at $8,000 \times g$ for $10 \mathrm{~min}$ at $4^{\circ} \mathrm{C}$, followed by washing the cell pellets in $3 \%$ of tri-sodium citrate buffer (Costa et al., 1996, Quigley et al., 2012) to remove clots or flakes. The DNA was then extracted using the MoBio Power Food Microbial DNA Isolation Kit (MoBio Laboratories Inc., Carlsbad, CA) or the PrepMan Ultra Sample Preparation Reagent (Applied Biosystems, Carlsbad, CA) following the manufacturers' instructions. Thirtythree of the milk samples for which DNA was extracted with the MoBio kit were tested by both LAMP and qPCR. For a more comprehensive qPCR analysis with DNA isolated by the PrepMan reagent, 57 milk samples were tested, including 22 samples that were also tested with the MoBio kit (Supplemental Table S1; https:// doi.org/10.3168/jds.2018-15306).

The DNA concentration and purity was measured with the Qubit 3.0 Fluorometer using the Qubit dsDNA HS Assay Kit (Life Technologies, Carlsbad, CA) and on a NanoDrop 2000c instrument (Thermo Scientific, Waltham, MA). A total of 1 to $2 \mu \mathrm{L}$, ranging from between 5 to $100 \mathrm{ng} / \mu \mathrm{L}$ of DNA, was used as template in the subsequent assays. The DNA extractions and all pre- or postamplification steps were performed in working areas separated from each other to prevent inlaboratory contamination.

\section{LAMP Primers Designed for the Detection of M. bovis}

To identify genes with high levels of DNA sequence conservation to use in the LAMP assay, $12 \mathrm{M}$. bovis genes required for basic cellular functions ( $f u s A$, gyr $B$, gsp $A, \operatorname{rpoB}, \operatorname{lep} A$, glpQ, gltx, tkt, adh1, pta2, oppD, and oppF; Register et al., 2015) were compared. All available $M$. bovis DNA sequences for these genes (ranging between 6 to 43 sequences per gene) were obtained from the NCBI Nucleotide database (www.ncbi.nlm.nih.gov/ nucleotide). The DNA sequence alignments were performed using the ClustalW alignment tool (Thompson et al., 1994); LAMP primers for oppD were designed with the PrimerExplorer V4 program (PrimerExplorer, Eiken Chemical Co. Ltd., Shanghai, China). The LAMP primers included outer primers (MycoF3; MycoB3), 2 inner primers (MycoFIP; MycoBIP), and 2 loop primers (MycoLA; MycoLB) with melting temperatures at $58^{\circ} \mathrm{C}$ (Table 1). To minimize the possibility of hairpin structures, the 3' ends of MycoF3 and MycoB3 and the 5 'ends of MycoFIP and MycoBIP were designed such that they exhibit a change in Gibbs free energy below $-4 \mathrm{kcal} / \mathrm{mol}$. The presence of secondary structures and possible formation of primer-dimers were tested with the OligoAnalyzer 3.1 software (OligoAnalyzer, Integrated DNA Technologies Inc., Skokie, IL). The specificity of the primers was assessed by a primer-BLAST search against the NCBI nucleotide (nr) database (Ye et al., 2012). Primers were regarded to be acceptable if they contained a minimum of 2 mismatches to unintended targets and at least 2 mismatches within the last $5 \mathrm{bp}$ of the $3^{\prime}$ end.

\section{Customization of LAMP Reaction Conditions}

The LAMP was performed in a final volume of 25 $\mu \mathrm{L}$, containing $1.4 \mathrm{~m} M$ of each deoxynucleotide triphos-

Table 1. Loop-mediated isothermal amplification primers targeting Mycoplasma bovis oppD

\begin{tabular}{lll}
\hline Primer & Sequence primer $5^{\prime} \rightarrow 3^{\prime}$ & Concentration $^{1}(\mathrm{n} M)$ \\
\hline MycoF3 & ACTAATCCAGCTCACCCTTA & 0.025 \\
MycoB3 & CGTTGCTGCTTTATGATGAC & 0.025 \\
MycoFIP & TGGGGTTCTTGAATTGAGATAAT-TACATGAGCGCTTATCTCG & 0.20 \\
MycoBIP & CAGATATGGCAAACTACCTATCGG-GGTGGTTCTTTTCATAGTCAA & 0.20 \\
MycoLA & TCTCATCATCATTTTCAGGTATAGC & 0.075 \\
MycoLB & TGACCCTTTTGCACCTAGAA & 0.075 \\
\hline
\end{tabular}

\footnotetext{
${ }^{1}$ Final concentrations used for testing Mycoplasma isolates and milk samples.
} 
phate (Promega, Madison, WI), $8 \mathrm{mM} \mathrm{MgSO}_{4}$ (New England BioLabs Inc., Ipswich, MA), $1 M$ betaine (Sigma-Aldrich, St Louis, MO), 0.32 U/ $\mu$ L of Bst 2.0 DNA polymerase (New England BioLabs Inc.), and Bst 2.0 DNA polymerase buffer (New England Biolabs Inc.). For assay development, final concentrations of primers MycoF3 and MycoB3 ranged from 0.0125 to 0.2 $\mu M$. Concentrations for the inner primers (MycoFIP and MycoBIP) ranged from 0.1 to $1.6 \mu M$. The loop primer (MycoLA and MycoLB) concentrations ranged from 0.0375 to $0.6 \mu M$. Template DNA was denatured for $3 \mathrm{~min}$ at $95^{\circ} \mathrm{C}$ and then placed on ice for $30 \mathrm{~s}$ before addition; LAMP was performed at $58^{\circ} \mathrm{C}$ with reaction times of $15,25,35,45$, or 55 min. Amplification was stopped by inactivating the Bst-polymerase $\left(95^{\circ} \mathrm{C}\right.$ for $3 \mathrm{~min}$ ). For each run, positive controls using gDNA equivalent to 1,000 copies of the $M$. bovis type strain Donetta PG45 ATCC 25523 genome were included and nontemplate reactions were used as negative controls. The LAMP products were detected by screening for fluorescence under UV light upon adding $3 \mu \mathrm{L}$ of SYBR Green I (100×; Life Technologies) into the reaction tubes. Amplification products were also subjected to capillary electrophoresis with the Bioanalyzer DNA 1000 kit (Agilent Technologies, Santa Clara, CA) or to $1.5 \%$ agarose gel electrophoresis to check for the typical, ladder-like band pattern generated during LAMP (Notomi et al., 2000; Tomita et al., 2008).

The analytical range, including the lower limit of $M$. bovis detection by the LAMP assay, was determined using 10-fold serial dilutions of M. bovis ATCC 25523 gDNA. Estimates of cell numbers and genome equivalents were based on the 1,003,404 bp M. bovis ATCC 25523 genome (Wise et al., 2011) and the average molecular weight of a base pair of $617.96 \mathrm{~g} / \mathrm{mol}$. Because of the poor utility of the LAMP assay, the analytical range of spiked milk samples was not assessed.

\section{qPCR Primer Design for Detection of M. bovis}

Mycoplasma bovis genes gltX (encoding glutamate tRNA ligase), gyrB (DNA gyrase subunit B), and gspA (glycerol-3-phosphate dehydrogenase) previously used for multilocus sequence typing (Register et al., 2015) were selected as qPCR targets. All qPCR primer and probes designed in the study are listed in Table 2. Primers were designed using Primer3 version 4.0.0 (Koressaar and Remm, 2007; Untergasser et al., 2012; Ye et al., 2012). All primers were designed to have a melting temperature at $58^{\circ} \mathrm{C}$ to $60^{\circ} \mathrm{C}$ and an amplicon size between 82 to $90 \mathrm{bp}$. The presence of secondary structures and possible primer-dimers were evaluated using OligoAnalyzer 3.1 software (OligoAnalyzer, Integrated DNA Technologies Inc.). The specificity of the primers and probes was assessed by a primer-BLAST search against the NCBI nucleotide (nr) database (Ye et al., 2012). Primers were regarded to be acceptable if they contained a minimum of 2 mismatches to unintended targets and at least 2 mismatches within the last 5 base pairs of the $3^{\prime}$ end.

\section{qPCR Assay Conditions}

Real-time PCR amplification was performed in 100$\mu \mathrm{L}, 96$-well plates on an ABI 7500 Fast Real-time PCR system (Applied Biosystems). Each well contained a final volume of $10 \mu \mathrm{L}$ of the reaction mix, with TaqMan Universal PCR Master Mix containing the AmpliTaq enzyme (Applied Biosystems) and $250 \mathrm{nM}$ of each primer and Taqman probe. Amplification was performed under standard conditions by incubating at $50^{\circ} \mathrm{C}$ for $2 \mathrm{~min}, 95^{\circ} \mathrm{C}$ for $10 \mathrm{~min}$, followed by 40 cycles of denaturation at $95^{\circ} \mathrm{C}$ for $15 \mathrm{~s}$, and then annealing and elongation at either 55,58 , or $60^{\circ} \mathrm{C}$ for $1 \mathrm{~min}$. Once primer and probe concentration as well as annealing

Table 2. Quantitative PCR primers and probes for Mycoplasma bovis

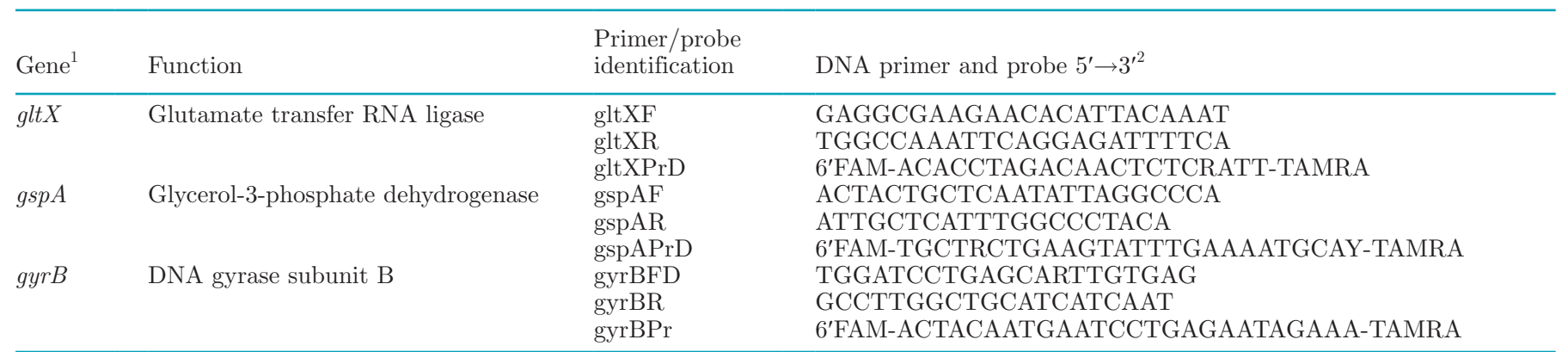

\footnotetext{
${ }^{1}$ The $g l t X$ assay was selected for further testing on Mycoplasma isolates and milk samples.
}

${ }^{2}$ The concentration of each primer was $250 \mathrm{nM}$. 
temperatures were chosen, DNA polymerases were also tested including the Kapa Probe fast qPCR kit Master Mix $(2 \times)$ Universal (Kapa Biosystems, Wilmington, MA), the Takara Premix Ex Taq $(2 \times$; Clontech Laboratories Inc., Takara Bio Company, Shiga, Japan), and the iTaq Supermix (Bio-Rad Laboratories, Hercules, $\mathrm{CA})$. After 40 PCR cycles, melting curves were generated by increasing the temperature from 60 to $95^{\circ} \mathrm{C}$ at $0.2^{\circ} \mathrm{C} / 10 \mathrm{~s}$ and recording the fluorescence. For each run, reactions containing gDNA equivalent to 1,000 copies of the $M$. bovis type strain Donetta PG45 ATCC 25523 were included was positive controls and nontemplate reactions were used as negative controls.

Amplification efficiencies and the analytical range, including the lower limit of $M$. bovis detection, were determined using 10 -fold serial dilutions of $M$. bovis ATCC 25523 gDNA. Estimates of cell numbers and genome equivalents were quantified as described for the LAMP assay [based on the 1,003,404-bp M. bovis ATCC 25523 genome (Wise et al., 2011) and the average molecular weight of a base pair of $617.96 \mathrm{~g} / \mathrm{mol}$ ]. The analytical range of $M$. bovis detection by $\mathrm{qPCR}$ was also determined after spiking PBS containing a known number of heat-killed M. bovis NM2012 cells into milk followed by using 10-fold serial dilutions of this suspension for gDNA extraction with the MoBio Power Food Kit and PrepMan Ultra reagent.

\section{Analytical and Diagnostic Accuracies}

The lower limits of detection were investigated for the LAMP and qPCR assays. Growth of Mycoplasma spp. in laboratory culture in combination with subsequent immunofluorescence staining was used as the reference for comparison. Laboratory culture results were used to confirm whether the sample was positive or negative, presuming that the reference method was $100 \%$ accurate. The following data were assessed for each of the LAMP and qPCR tests using culture as the reference test: $M$. bovis prevalence in the milk samples tested, assay accuracy and inaccuracy, sensitivity defined as the proportion of culture-positive samples that have a testpositive status, specificity defined as the proportion of culture-negative samples that have a test-negative status, and the type I and II errors indicating the possibility to obtain false positive $(\alpha)$ or false-negative $(\beta)$ test results (Parikh et al., 2008; Drobatz, 2009; Wold Organisation for Animal Health, 2010). A 2-sample test for proportions (Z-test) was used to compare the sensitivity of qPCR using both DNA extraction methods. Similarly, a Z-test was used to compare the sensitivity of qPCR using the PrepMan Ultra reagent to the sensitivity of LAMP assay following DNA extraction with the MoBio kit. In addition, McNemar's test was used to compare the sensitivities of qPCR and LAMP following DNA extraction with the MoBio kit. Specificities of the assays were compared in a similar manner.

\section{RESULTS}

\section{LAMP Assay to Detect M. bovis}

Comparisons of the DNA sequences for $12 \mathrm{M}$. bovis genes required for basic cellular functions ( $f u s A$, gyrB, gsp $A$, rроB, lepA, glpQ, gltx, tkt, adh1, pta2, oppD, and $o p p F$; Register et al., 2015) resulted in the identification of $o p p D$ as a suitable target for LAMP assay development. The oppD gene, encoding an oligopeptide transport ATP-binding protein (oligopeptide permease D), was selected because it had the highest level of nucleotide conservation between the genes examined (100\% nucleotide sequence identity) and was amenable to primer design for the LAMP assay.

Different $о p p D$ primer concentrations were compared and $0.025 \mu \mathrm{M}$ outer primers (MycoF3; MycoB3), 0.2 $\mu M$ inner primers (MycoFIP; MycoBIP), and 0.075 $\mu M$ loop primers (MycoLA; MycoLB) yielded the most consistent results (Figure 1 and 2). The use of higher primer concentrations (MycoF3 and MycoB3, between 0.05 to $0.2 \mu M$; MycoFIP and MycoBIP, between 0.4 to $1.6 \mu M$; and MycoLA and MycoLB, between 0.15 to $0.6 \mu M)$ resulted in false-positive outcomes [e.g., Supplemental Figure S1 (top panel); https://doi.org/ 10.3168/jds.2018-15306], most likely due to the formation of primer dimers [Supplemental Figure S1 (bottom panel)].

The LAMP products were obtained after 45 and 55 min when 1,000 genome equivalents of $M$. bovis ATCC 25523 were used as a template (Supplemental Figure S2; https://doi.org/10.3168/jds.2018-15306). No amplification was observed after 15,25 , or $35 \mathrm{~min}$; therefore, 55 min was used to access the analytical specificity and sensitivity of the assay.

\section{Accuracy of the LAMP Assay}

The lower detection limit of the oppD LAMP assay when $M$. bovis ATCC 25523 gDNA was used as a template was 10 genome equivalents per reaction, corresponding to $10^{4}$ cells $/ \mathrm{mL}$, assuming 1 genome copy per cell (Figure 2). The LAMP assay correctly detected all $13 \mathrm{M}$. bovis isolates and was negative for 6 out of the 8 non-bovis Mycoplasma tested (Table 3). Two $M$. bovigenitalium isolates (15M0599_27 and 15M0701_17) were found to be positive with the LAMP assay. 
For DNA extracted from 33 milk samples using the MoBio Power Food kit, 14 out of 16 samples found to contain $M$. bovis according to standard laboratory culture-based methods were also positive by LAMP (Table 4). Milk harboring M. arginini (1 sample) and M. californicum (3 samples) were negative for $M$. bovis with LAMP. The LAMP assay was also negative for 3 out of 4 samples containing $M$. bovigenitalium and 7 out of 9 samples that tested negative for any Mycoplasma species (Table 4). For the 3 potentially false-positive results (samples 15M0599_27, AM15, and KM15), DNA extractions were repeated and LAMP positive reactions were confirmed. It was notable that the $M$. bovis LAMP assay was positive for both the whole milk sample 15M0599_27 (Table 4) and the M. bovigenitalium isolate enriched from that sample (Table 3).

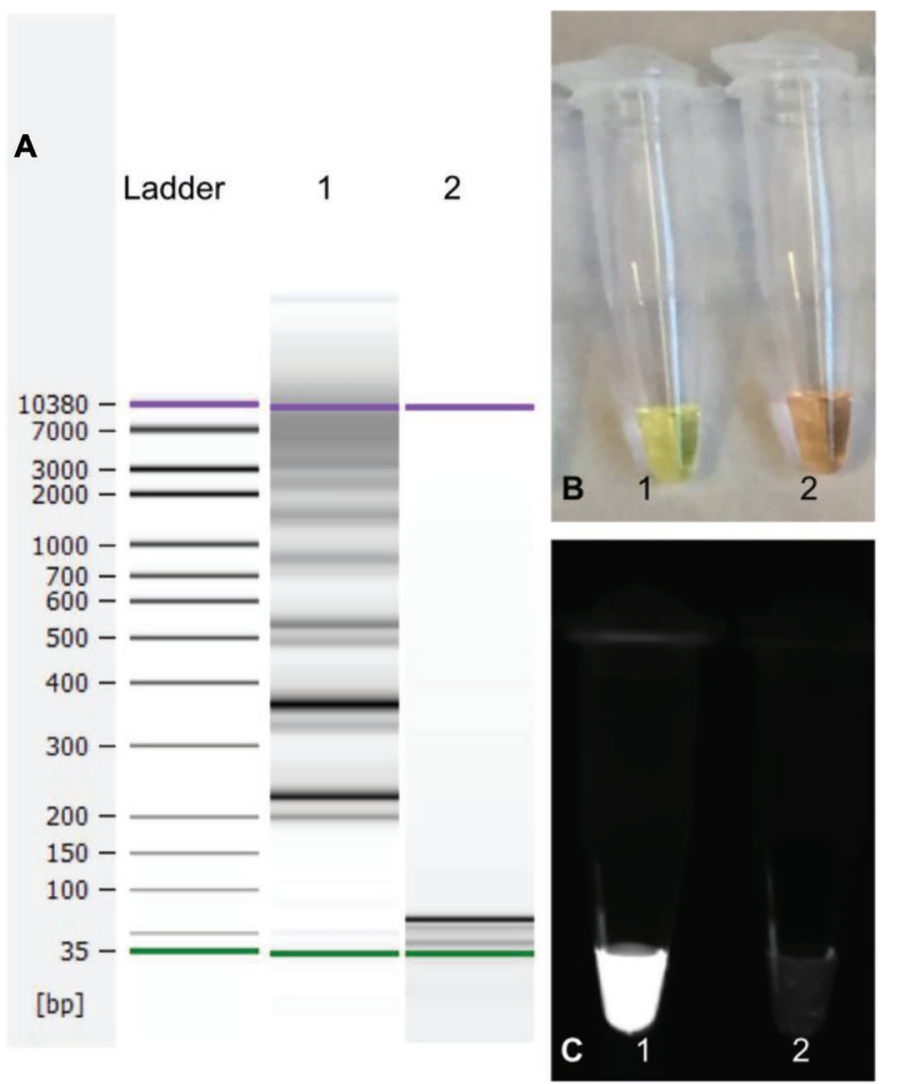

Figure 1. Visualization of loop-mediated isothermal amplification (LAMP) products. The LAMP products were separated by (A) capillary gel electrophoresis or stained with SYBR Green (Life Technologies, Carlsbad, CA) for observation under (B) visible and (C) UV light. 1 = positive control, containing 1,000 copies of genomic DNA of Mycoplasma bovis type strain Donetta PG45 ATCC 25523; 2 $=$ negative control. The LAMP was performed using a final concentration of $0.025 \mu M$ outer primers (MycoF3; MycoB3), $0.2 \mu M$ inner primers (MycoFIP; MycoBIP), and $0.075 \mu M$ loop primers (MycoLA; MycoLB).
Although the PrepMan Ultra Reagent was also used to extract DNA from milk for LAMP testing, that method was not pursued further because its application yielded inconsistent results (data not shown).

\section{qPCR Assay to Detect M. bovis}

To develop qPCR assays for gltX (encoding glutamate tRNA ligase), gyrB (DNA gyrase subunit B), and gspA (glycerol-3-phosphate dehydrogenase), different primer concentrations and annealing temperatures were tested using the TaqMan Universal PCR Master Mix (containing the AmpliTaq enzyme). The most consistent amplification efficiencies were obtained with the gltX primer-probe pair, at a concentration of 250 $\mathrm{n} M$ and amplification performed at $58^{\circ} \mathrm{C}$. Next, we compared different qPCR enzymes and found that the iTaq Master Mix required shorter run times and yielded high amplification efficiencies (Supplemental Figure S3; https://doi.org/10.3168/jds.2018-15306). Therefore, this enzyme, in combination with the $g l t X$ qPCR assay, was used in subsequent tests on DNA extracted from milk or heat-killed Mycoplasma isolates (Table 3).

\section{Accuracy of the gltX qPCR Assay}

The lower detection limit for the glt $X$ assay was set at a cycle threshold of 37 , and this constituted between 10 to 100 genome equivalents per reaction. Those numbers are approximately equivalent to $1 \times 10^{4}$ to $1 \times$ $10^{5}$ cells $/ \mathrm{mL}$, assuming 1 genome copy per cell (data not shown). The lower detection limit of $M$. bovis cells in milk was also equivalent to approximately $1 \times 10^{4}$ to $1 \times 10^{5} \mathrm{cfu} / \mathrm{mL}$ for both DNA extraction methods (Supplemental Figure S4; https://doi.org/10.3168/jds .2018-15306).

The glt $X$ qPCR assay correctly identified 13 heatinactivated $M$. bovis isolates (Table 3). Out of the 8 non-bovis isolates examined, 1 isolate of $M$. bovigenitalium (15M0701_17) and 1 isolate of M. californicum (150620_89) tested positive by qPCR (Table 3).

For DNA extracted from 33 milk samples with the MoBio Power Food kit, the qPCR assay was positive for 14 out of $16 \mathrm{M}$. bovis-positive samples (Table 4). The 2 samples (15M753_2 and 15M753_5) that were negative for $M$. bovis by qPCR were also negative according to the oppD LAMP assay. One of 4 milk samples containing $M$. bovigenitalium was positive in the glt $X \mathrm{qPCR}$ assay (15M0616_40). The remaining $16 \mathrm{M}$. bovis negative milk samples were also negative for $M$. bovis according to qPCR (Table 4).

For testing the PrepMan Ultra reagent with the qPCR assay, a total of 57 milk samples were included 
Table 3. Evaluation of loop-mediated isothermal amplification (LAMP) and quantitative PCR (qPCR) assays on heat-inactivated Mycoplasma cultures

\begin{tabular}{|c|c|c|c|}
\hline Culture result ${ }^{1}$ & $\begin{array}{l}\text { Milk sample identification } \\
\text { used for cultivation }\end{array}$ & LAMP $^{2}$ & $\mathrm{qPCR}^{2}$ \\
\hline Mycoplasma arginini & 15M0599_19 & - & - \\
\hline Mycoplasma bovigenitalium & 15M0599_27 & + & - \\
\hline M. bovigenitalium & 15M0616_40 & - & - \\
\hline M. bovigenitalium & 15M0616_105 & - & - \\
\hline M. bovigenitalium & 15M0701_17 & + & + \\
\hline Mycoplasma bovis & 15M0599_28 & + & + \\
\hline M. bovis & 15M0616_70 & + & + \\
\hline M. bovis & 15M0620_12 & + & + \\
\hline M. bovis & 15M0620_23 & + & + \\
\hline M. bovis & 15M0620_45 & + & + \\
\hline M. bovis & 15M0620_116 & + & + \\
\hline M. bovis & 15M0620_137 & + & + \\
\hline M. bovis & 15M0620_165 & + & + \\
\hline$M$. bovis & 15M0649_90 & + & + \\
\hline M. bovis & 15M0671_98 & + & + \\
\hline M. bovis & 15M0681_1 & + & + \\
\hline M. bovis & 15M0693_11 & + & + \\
\hline M. bovis & 15M0697_1 & + & + \\
\hline Mycoplasma californicum & 15M0616_34 & - & - \\
\hline M. californicum & 15M0620_89 & - & + \\
\hline M. californicum & 15M0693_15 & - & - \\
\hline
\end{tabular}

${ }^{1}$ Mycoplasma species were identified by culture and fluorescent staining (Baas and Jasper, 1972).

${ }^{2} \mathrm{DNA}$ was amplified from cells that were heat-killed at $60^{\circ} \mathrm{C}$ and then frozen at $-20^{\circ} \mathrm{C}$, for which subsequent DNA extraction and purification steps were not performed. Positive test results are indicated by a plus $(+)$ and negative test results by a minus $(-)$.

(Table 5). All 21 of the samples that tested positive for $M$. bovis according to laboratory culture were also positive with the gltX qPCR assay (Table 5). Out of the remaining 36 milk samples that were found to lack any viable $M$. bovis or contained other $M y$ coplasma (or related) species, 2 samples (15M718_22
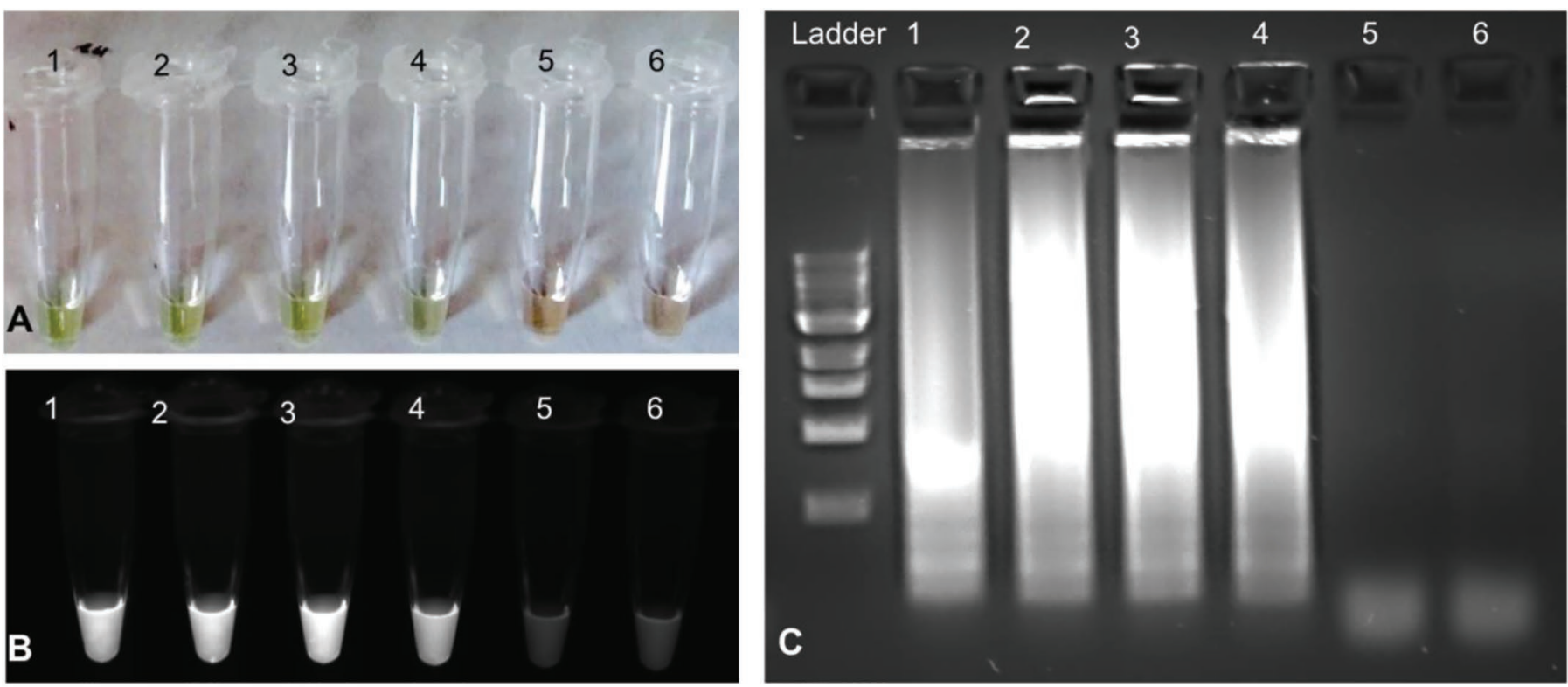

Figure 2. Analytical sensitivity of the loop-mediated isothermal amplification (LAMP) assay. The LAMP products were stained by SYBR Green I (Life Technologies, Carlsbad, CA) for visual observation under (A) visible and (B) UV light. (C) The LAMP products were also separated by gel electrophoresis. The numbers indicate genome equivalents of Mycoplasma bovis type strain Donetta PG45 ATCC 25523 used for LAMP: (1) $10^{4},(2) 10^{3},(3) 10^{2}$, (4) $10^{1}$, (5) $10^{0}$, and (6) negative control. 
Table 4. Evaluation of loop-mediated isothermal amplification (LAMP) and quantitative PCR (qPCR) assays on DNA extracted from milk using the MoBio Power Food kit (MoBio Laboratories Inc., Carlsbad, CA)

\begin{tabular}{|c|c|c|c|}
\hline Culture result ${ }^{1}$ & $\begin{array}{l}\text { Sample } \\
\text { identification }\end{array}$ & LAMP $^{2}$ & $\mathrm{qPCR}^{2}$ \\
\hline $\begin{array}{l}\text { Mycoplasma arginini } \\
\text { Mycoplasma bovigenitalium } \\
\text { M. bovigenitalium } \\
\text { M. bovigenitalium } \\
\text { M. bovigenitalium } \\
\text { Mycoplasma bovis } \\
\text { M. bovis } \\
\text { M. bovis } \\
\text { M. bovis } \\
\text { M. bovis } \\
\text { M. bovis } \\
\text { M. bovis } \\
\text { M. bovis } \\
\text { M. bovis } \\
\text { M. bovis } \\
\text { M. bovis } \\
\text { M. bovis } \\
\text { M. bovis } \\
\text { M. bovis } \\
\text { M. bovis } \\
\text { M. bovis } \\
\text { Mycoplasma californicum } \\
\text { M. californicum } \\
\text { M. californicum } \\
\text { Negative for Mycoplasma }\end{array}$ & 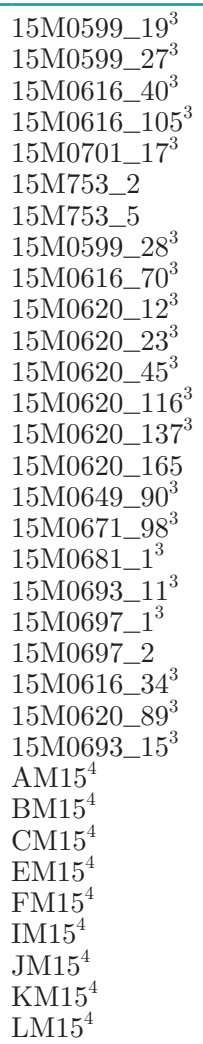 & $\begin{array}{l}- \\
+ \\
- \\
- \\
- \\
- \\
- \\
+ \\
+ \\
+ \\
+ \\
+ \\
+ \\
+ \\
+ \\
+ \\
+ \\
+ \\
+ \\
+ \\
+ \\
- \\
- \\
- \\
+ \\
- \\
- \\
- \\
- \\
- \\
- \\
+ \\
-\end{array}$ & $\begin{array}{l}- \\
- \\
+ \\
- \\
- \\
- \\
- \\
+ \\
+ \\
+ \\
+ \\
+ \\
+ \\
+ \\
+ \\
+ \\
+ \\
+ \\
+ \\
+ \\
+ \\
- \\
- \\
- \\
- \\
- \\
- \\
- \\
- \\
- \\
- \\
- \\
-\end{array}$ \\
\hline
\end{tabular}

${ }^{1}$ Mycoplasma species were identified by culture and fluorescent staining (Baas and Jasper, 1972).

${ }^{2}$ Positive test results are indicated by a plus $(+)$ and negative test results by a minus $(-)$.

${ }^{3}$ Mycoplasma milk samples with single culture isolates shown in Table 3.

${ }^{4}$ The milk sample was collected from a single cow. All other samples were from bulk tanks.

and 15M0616_40) were positive for M. bovis by qPCR (Table 5). Sample 15M0616_40 was also positive according to qPCR following DNA extraction with the MoBio Power Food kit (Table 4). These results were confirmed in repetitions of the assay following repeated DNA extractions.

\section{Comparison of Assay Accuracy}

Assuming that enrichment in laboratory culture medium followed by species identification by immunological methods is the reference test for Mycoplasma, the overall accuracy of the qPCR assay when the MoBio Power Food kit was applied for DNA extraction was higher $(90.9 \%)$ than the LAMP assay $(84.8 \%$; Table 6). Although we noted some differences between the samples tested (Supplemental Table 1; https://doi.org/ 10.3168/jds.2018-15306), qPCR after DNA extraction using the PrepMan Ultra reagent was also useful for the accurate detection of $M$. bovis (96.5\%, accuracy). By comparison, LAMP was unsuccessful on DNA extracted from milk with the PrepMan Ultra reagent method; hence, test accuracy is only available for qPCR using this extraction method. The probability of test-negative given culture-negative status was higher for qPCR using the MoBio Power Food and the PrepMan Ultra DNA extraction methods (94.1 and $94.4 \%$, respectively) compared with LAMP using the MoBio extraction method (82.4\%; Table 6$)$. With the exception of the identical sensitivity estimates for LAMP and qPCR following DNA extraction using the MoBio kit, we observed only numerical differences $(P>0.05)$ between the accuracy (sensitivity or specificity) of qPCR following either DNA extraction methods and between the latter and LAMP following DNA extraction using the MoBio kit. 
Table 5. Evaluation of the gltX quantitative PCR (qPCR) assay on DNA extracted from milk using the PrepMan Ultra reagent (Applied Biosystems, Carlsbad, CA)

\begin{tabular}{|c|c|c|}
\hline Culture result $^{1}$ & $\begin{array}{l}\text { Sample } \\
\text { identification }\end{array}$ & $\mathrm{qPCR}^{2}$ \\
\hline Acholeplasma laidlawii & $15 \mathrm{M} 730 \_44$ & - \\
\hline A. laidlawii & 15M753_59 & - \\
\hline Mycoplasma alkalescens & $15 \mathrm{M} 720$ & - \\
\hline M. alkalescens & 15M720_20 & - \\
\hline M. alkalescens & $15 \mathrm{M} 753 \_80$ & - \\
\hline M. alkalescens & 15M753_52 & - \\
\hline M. alkalescens & 15M753_119 & - \\
\hline Mycoplasma arginini & 15M0599_19 & - \\
\hline M. arginini & 15M753_57 & - \\
\hline Mycoplasma bovigenitalium & $15 \mathrm{M} 0599 \_27^{3}$ & - \\
\hline M. bovigenitalium & $15 \mathrm{M} 0616 \_40^{3}$ & + \\
\hline M. boviqenitalium & $15 \mathrm{M} 0616 \_105^{3}$ & - \\
\hline M. boviqenitalium & $15 \mathrm{M} 070117^{3}$ & - \\
\hline M. bovigenitalium & 15M720_118 & - \\
\hline M. bovigenitalium & 15M730_47 & - \\
\hline M. bovigenitalium & 15M746_49 & - \\
\hline M. boviqenitalium & $15 \mathrm{M} 75356$ & - \\
\hline M. bovigenitalium & $15 \mathrm{M} 753 \_60$ & - \\
\hline M. bovigenitalium & $15 \mathrm{M} 753 \_88$ & - \\
\hline M. bovigenitalium & 15M863_14 & - \\
\hline M. bovigenitalium & 15M863_63 & - \\
\hline M. boviqenitalium & $15 \mathrm{M} 866 \quad 32$ & - \\
\hline Mycoplasma bovis & $15 \mathrm{M} 059928^{3}$ & + \\
\hline M. bovis & $15 \mathrm{M} 0616 \_70^{3}$ & + \\
\hline M. bovis & $15 \mathrm{M} 0620 \_12^{3}$ & + \\
\hline M. bovis & $15 \mathrm{M} 06202_{23}^{3}$ & + \\
\hline M. bovis & $15 \mathrm{M} 0620-45^{3}$ & + \\
\hline M. bovis & $15 \mathrm{M} 0620 \_116^{3}$ & + \\
\hline M. bovis & 15M0620_137 $7^{3}$ & + \\
\hline M. bovis & $15 \mathrm{M} 0620165^{3}$ & + \\
\hline M. bovis & $15 \mathrm{M} 0649 \_90^{3}$ & + \\
\hline M. bovis & 15M0671_98 & + \\
\hline M. bovis & $15 \mathrm{M} 06811^{3}$ & + \\
\hline M. bovis & 15M0693_11 & + \\
\hline M. bovis & $15 \mathrm{M} 06971^{3}$ & + \\
\hline M. bovis & $15 \mathrm{M} 0697 \_2^{3}$ & + \\
\hline M. bovis & 15M720_25 & + \\
\hline M. bovis & 15M720_46 & + \\
\hline M. bovis & 15M730_46 & + \\
\hline M. bovis & 15M863_24 & + \\
\hline M. bovis & $15 \mathrm{M} 86350$ & + \\
\hline M. bovis & 15M863_62 & + \\
\hline M. bovis & $15 \mathrm{M} 866 \_150$ & + \\
\hline Mycoplasma californicum & $15 \mathrm{M} 061634^{3}$ & - \\
\hline M. californicum & $15 \mathrm{M} 0620 \_89^{3}$ & - \\
\hline M. californicum & $15 \mathrm{M} 0693 \_15^{3}$ & - \\
\hline M. californicum & 15M753_58 & - \\
\hline M. californicum & 15M753_90 & - \\
\hline M. californicum & 15M746_48 & - \\
\hline M. californicum & 15M863_39 & - \\
\hline M. californicum & 15M866_103 & - \\
\hline \multirow{6}{*}{ Negative for Mycoplasma } & 15M718_4 & - \\
\hline & 15M718_22 & + \\
\hline & 15M720_51 & - \\
\hline & $15 \mathrm{M} 720 \_85$ & - \\
\hline & 15M730_45 & - \\
\hline & 15M783_14 & - \\
\hline
\end{tabular}

${ }^{1}$ Mycoplasma species were identified by culture and fluorescent staining (Baas and Jasper, 1972).

${ }^{2}$ Positive test results are indicated by a plus $(+)$ and negative test results by a minus $(-)$.

${ }^{3}$ DNA was also recovered using the MoBio Power Food kit (MoBio Laboratories Inc., Carlsbad, CA) and used as template for loop-mediated isothermal amplification and qPCR (Table 3). The MoBio Power Food kit DNA extraction method was not applied to the other milk samples included in this table.

\section{DISCUSSION}

The goal of our research was to provide low-cost, simple methods that could be widely adopted by milk quality laboratories, practitioners, and dairy producers for Mycoplasma disease prevention and pathogen containment. We developed LAMP and qPCR assays that enable rapid and accurate detection of $M$. bovis in laboratory culture suspensions and in raw bovine milk. These assays were validated on milk and corresponding isolates collected from dairies in the Central Valley of California. The findings indicate the utility of the assays for detection of $M$. bovis in that important dairy production region of the United States. Moreover, because both methods are rapid (completed in $<2 \mathrm{~h}$ ) and relatively low cost, they have benefits over standard Mycoplasma laboratory culturing and identification methods.

The gltX qPCR assay performed better than LAMP on raw milk. This conclusion was based on the finding that $\mathrm{qPCR}$ was possible on gDNA extracted from milk when either the MoBio Power Food kit or PrepMan Ultra reagent was applied and the higher proportion of correctly identified positive and negative samples using culture-based identification as the reference. Furthermore, qPCR had a faster total reaction time with the PrepMan Ultra reagent combined with the iTaq polymerase compared with LAMP. The time required to perform the assay, including the DNA extraction step and $\mathrm{qPCR}$ amplification, was within $1 \mathrm{~h}$, a period of time that is lower compared with other $M$. bovis PCR assays (Rossetti et al., 2010; Gioia et al., 2016; Parker et al., 2017; Behera et al., 2018). Several other qPCR assays have been developed for $M$. bovis and targeted other genes, including uvrC (coding for deoxyribodipyrimidine photolyase, enzyme in the DNA-repair system; Clothier et al., 2010; Rossetti et al., 2010; Naikare et al., 2015), oppD (coding for an oligopeptide permease; Sachse et al., 2010), and fusA (coding for elongation factor G; Boonyayatra et al., 2012). Comparisons between these assays could result in the identification of combinations that result in an increased accuracy of detection. Notably, the assays performed equally well or were more sensitive for the detection of low quantities of $M$. bovis cells compared with the $g l t X$ assay described here. However, outcomes can depend on milk composition, DNA extraction methods, and qPCR conditions used. Additional steps to improve this method could include multiplex qPCR to identify a broader range of Mycoplasma and contaminant species (e.g., Parker et al., 2017) and more extensive tests on pooled milk samples and milk collected from other geographic locations. 
Table 6. Test accuracy estimates for loop-mediated isothermal amplification (LAMP) and quantitative PCR (qPCR) assays to detect Mycoplasma bovis using culture as the reference method $^{1}$

\begin{tabular}{|c|c|c|c|}
\hline Item & $\begin{array}{l}\text { LAMP } \\
\text { (MoBio) }\end{array}$ & $\begin{array}{c}\mathrm{qPCR} \\
\text { (MoBio) }\end{array}$ & $\begin{array}{c}\text { qPCR } \\
\text { (PrepMan Ultra) }\end{array}$ \\
\hline Prevalence of positive samples in the milk sample pool, \% (no.) & $\begin{array}{c}48.5 \\
(16 / 33)\end{array}$ & $\begin{array}{l}48.5 \\
(16 / 33)\end{array}$ & $\begin{array}{l}36.8 \\
(21 / 57)\end{array}$ \\
\hline Assay inaccuracy, \% & 15.2 & 9.1 & 3.5 \\
\hline Sensitivity, \% (95\% CI) & $\begin{array}{l}87.5 \\
(71.3,100)\end{array}$ & $\begin{array}{l}87.5 \\
(71.3,100)\end{array}$ & $\begin{array}{c}100 \\
(100,100)\end{array}$ \\
\hline False-positive rate - type I error $(\alpha), \%$ & 17.6 & 5.9 & 5.6 \\
\hline False-negative rate - type II error $(\beta), \%$ & 12.5 & 12.5 & 0 \\
\hline
\end{tabular}

${ }^{1}$ Estimates are calculated on the basis of a total of 33 samples tested with the MoBio extraction kit (MoBio Laboratories Inc., Carlsbad, CA) for both LAMP and qPCR assays (Table 4) and 57 (Table 5) samples tested by qPCR following DNA extraction with the PrepMan Ultra reagent (Applied Biosystems, Carlsbad, CA). See also Supplemental Table S1 for a summary of all samples used for each test (https://doi.org/10.3168/ jds.2018-15306).

The LAMP uses a DNA polymerase and sets of primers that result in a synchronized sequence of hybridization and synthesis, leading to isothermal amplification (Notomi et al., 2000; Tomita et al., 2008). The LAMP is reported to be more sensitive than PCR, and because LAMP is performed at a single temperature there is no need for specialized equipment (Fu et al., 2011; Notomi et al., 2000; Poon et al., 2005; Tomita et al., 2008; Fu et al., 2011; Martínez-Valladares and Rojo-Vazquez, 2016). Overall, LAMP performed well on purified DNA; however, even under optimal conditions, the assay was highly susceptible to contamination and DNA preparation and LAMP had to be performed in separate locations in the laboratory, with only a limited number of replicates per day. Moreover, LAMP was unsuccessful on DNA extracted from milk with the PrepMan Ultra reagent, a method that does not include a DNA purification step.

Three LAMP assays for $M$. bovis were previously developed and used to detect Mycoplasma in clinical (nasal, tracheal, lung) samples and on milk positive for M. bovis, Staphylococcus aureus, and Streptococcus agalactiae (Bai et al., 2011; Higa et al., 2016; Ashraf et al., 2018). However, those assays were not tested on milk from healthy or asymptomatic cows or used to distinguish between different Mycoplasma species. The LAMP assay developed herein exhibited an equal or higher sensitivity and lower specificity compared the LAMP assays published previously (Bai et al., 2011; Higa et al., 2016; Ashraf et al., 2018). The lower specificity was the result of milk samples that were positive or negative for $M$. bovis according to LAMP amplification, but yielded different results according to bacterial culture. Comparing sensitivity or specificity estimates in our study yielded only numerical differences between the assays and DNA extraction methods. A larger study should be employed to further explore differences in assay accuracy given the different extraction methods.

Notably, $1 M$. bovigenitalium isolate was identified as $M$. bovis by both LAMP and qPCR assays. This potentially indicates the presence of a $M$. bovis co-culture or taxonomic misassignment. Among the milk samples, several that were designated as negative for $M$. bovis yielded positive amplification results by either assay. However, to be out of compliance with culture results is possible due to the detection of nucleic acids from dead or nonculturable $M$. bovis cells by amplification in culture-negative samples (Bradbury and McClenaghan, 1982; Fu et al., 2011). Alternatively, fastidious Mycoplasma spp. might have been overgrown by other bacteria present in the milk (Bradbury and McClenaghan, 1982).

In conclusion, we developed and compared 2 assays for $M$. bovis detection in bovine milk. Although the qPCR assay was more robust than the LAMP assay, validation studies on individual and pooled milk samples are still required. Moreover, the $\mathrm{qPCR}$ approach can be improved by the incorporation of multiple target detection (multiplex) methods, such as those for the detection for Mycoplasma species broadly and M. bovis specifically.

\section{ACKNOWLEDGMENTS}

Funds for this study were provided by The California Dairy Research Foundation. The funding agency did not participate in study design, data collection, or interpretation of the data. Support for Marco was provided, in part, by The Agricultural Experiment Station at the University of California, Davis. 


\section{REFERENCES}

Ashraf, A., M. Imran, T. Yaqub, M. Tayyab, W. Shehzad, C. N. Mingala, and Y. F. Chang. 2018. Development and validation of a loop-mediated isothermal amplification assay for the detection of Mycoplasma bovis in mastitic milk. Folia Microbiol. (Praha) 63:373-380. https://doi.org/10.1007/s12223-017-0576-x.

Baas, E. J., and D. E. Jasper. 1972. Agar block technique for identification of mycoplasmas by use of fluorescent antibody. Appl. Microbiol. 23:1097-1100

Bai, Z. D., L. Shi, C. M. Hu, X. Chen, J. J. Qi, X. L. Ba, Q. J. Peng, Y. Y. Chen, H. C. Chen, and A. Z. Guo. 2011. Development of a loop-mediated isothermal amplification assay for sensitive and rapid detection of Mycoplasma bovis. Afr. J. Biotechnol. 10:1233312338.

Bar, D., L. W. Tauer, G. Bennett, R. N. Gonzalez, J. A. Hertl, Y. H. Schukken, H. F. Schulte, F. L. Welcome, and Y. T. Grohn. 2008. The cost of generic clinical mastitis in dairy cows as estimated by using dynamic programming. J. Dairy Sci. 91:2205-2214. https:// doi.org/10.3168/jds.2007-0573.

Bar-Gal, G. K., S. E. Blum, L. Hadas, R. Ehricht, S. Monecke, and G. Leitner. 2015. Host specificity of Staphylococcus aureus causing intramammary infections in dairy animals assessed by genotyping and virulence genes. Vet. Microbiol. 176:143-154. https://doi.org/ 10.1016/j.vetmic.2015.01.007.

Bayoumi, F. A., T. B. Farver, B. Bushnell, and M. Oliveria. 1988. Enzootic mycoplasmal mastitis in a large dairy during an eight-year period. J. Am. Vet. Med. Assoc. 192:905-909.

Behera, S., R. Rana, P. K. Gupta, D. Kumar, Sonal, V. Rekha, T. R. Arun, and D. Jena. 2018. Development of real-time PCR assay for the detection of Mycoplasma bovis. Trop. Anim. Health Prod. 50:875-882. https://doi.org/10.1007/s11250-018-1510-1.

Boonyayatra, S., L. K. Fox, T. E. Besser, A. Sawant, J. M. Gay, and Z. Raviv. 2012. A PCR assay and PCR-restriction fragment length polymorphism combination identifying the 3 primary Mycoplasma species causing mastitis. J. Dairy Sci. 95:196-205.

Bradbury, J. M., and M. McClenaghan. 1982. Detection of mixed Mycoplasma species. J. Clin. Microbiol. 16:314-318.

Cai, H. Y., P. Bell-Rogers, L. Parker, and J. F. Prescott. 2005. Development of a real-time PCR for detection of Mycoplasma bovis in bovine milk and lung samples. J. Vet. Diagn. Invest. 17:537-545.

Caswell, J. L., and M. Archambault. 2007. Mycoplasma bovis pneumonia in cattle. Anim. Health Res. Rev. 8:161-186. https://doi.org/ 10.1017/S1466252307001351.

Clothier, K. A., D. M. Jordan, C. J. Thompson, J. M. Kinyon, T. S. Frana, and E. L. Strait. 2010. Mycoplasma bovis real-time polymerase chain reaction assay validation and diagnostic performance. J. Vet. Diagn. Invest. 22:956-960.

Costa, E. O., A. C. Carciofi, P. A. Melville, M. S. Prada, and U. Schalch. 1996. Prototheca sp. outbreak of bovine mastitis. Zentralbl. Veterinarmed. B. 43:321-324.

Drobatz, K. J. 2009. Measures of accuracy and performance of diagnostic tests. J. Vet. Cardiol. 11(Suppl 1):S33-S40. https://doi.org/ 10.1016/j.jvc.2009.03.004.

Fox, L. K. 2012. Mycoplasma mastitis: Causes, transmission, and control. Vet. Clin. North Am. Food Anim. Pract. 28:225-237. https:/ /doi.org/10.1016/j.cvfa.2012.03.007.

Fox, L. K., and J. M. Gay. 1993. Contagious mastitis. Vet. Clin. North Am. Food Anim. Pract. 9:475-487.

Fox, L. K., J. H. Kirk, and A. Britten. 2005. Mycoplasma mastitis: A review of transmission and control. J. Vet. Med. B Infect. Dis. Vet. Public Health 52:153-160. https://doi.org/10.1111/j.1439-0450 2005.00845.x.

Fu, S., G. Qu, S. Guo, L. Ma, N. Zhang, S. Zhang, S. Gao, and Z. Shen. 2011. Applications of loop-mediated isothermal DNA amplification. Appl. Biochem. Biotechnol. 163:845-850. https://doi.org/ 10.1007/s12010-010-9088-8.

Gioia, G., B. Werner, D. V. Nydam, and P. Moroni. 2016. Validation of a Mycoplasma molecular diagnostic test and distribution of mycoplasma species in bovine milk among New York State dairy farms. J. Dairy Sci. 99:4668-4677. https://doi.org/10.3168/jds 2015-10724

González, R. N., D. E. Jasper, T. B. Farver, R. B. Bushnell, and C. E. Franti. 1988. Prevalence of udder infections and mastitis in 50 California dairy herds. J. Am. Vet. Med. Assoc. 193:323-328.

Halasa, T., K. Huijps, O. Osteras, and H. Hogeveen. 2007. Economic effects of bovine mastitis and mastitis management: a review. Vet. Q. 29:18-31.

Hale, H. H., C. F. Helmboldt, W. N. Plastridge, and E. F. Stula 1962. Bovine mastitis caused by a Mycoplasma species. Cornell Vet. 52:582-591.

Higa, Y., R. Uemura, W. Yamazaki, S. Goto, Y. Goto, and M. Sueyoshi. 2016. An improved loop-mediated isothermal amplification assay for the detection of Mycoplasma bovis. J. Vet. Med. Sci. 78:1343-1346. https://doi.org/10.1292/jvms.15-0459.

Jasper, D. E. 1977. Mycoplasma and mycoplasma mastitis. J. Am. Vet. Med. Assoc. 170:1167-1172.

Jasper, D. E., J. D. Dellinger, M. H. Rollins, and H. D. Hakanson. 1979. Prevalence of mycoplasmal bovine mastitis in California. Am. J. Vet. Res. 40:1043-1047.

Kirk, J. H., K. Glenn, L. Ruiz, and E. Smith. 1997. Epidemiologic analysis of Mycoplasma spp isolated from bulk-tank milk samples obtained from dairy herds that were members of a milk cooperative. J. Am. Vet. Med. Assoc. 211:1036-1038.

Koressaar, T., and M. Remm. 2007. Enhancements and modifications of primer design program Primer3. Bioinformatics 23:1289-1291.

Kralik, P., and M. Ricchi. 2017. A basic guide to real time PCR in microbial diagnostics: Definitions, parameters, and everything. Front. Microbiol. 8:108. https://doi.org/10.3389/fmicb.2017.00108.

Lane, D. J. 1991. 16S/23S rRNA sequencing. Pages 115-175 in Nucleic Acid Techniques in Bacterial Systematics. M. Goodfellow, and E. Stackebrandt, ed. Wiley, Chichester, UK.

Li, Y., P. Fan, S. Zhou, and L. Zhang. 2017. Loop-mediated isothermal amplification (LAMP): A novel rapid detection platform for pathogens. Microb. Pathog. 107:54-61. https://doi.org/10.1016/j .micpath.2017.03.016.

Martínez-Valladares, M., and F. A. Rojo-Vazquez. 2016. Loop-mediated isothermal amplification (LAMP) assay for the diagnosis of fasciolosis in sheep and its application under field conditions. Parasit. Vectors 9:73. https://doi.org/10.1186/s13071-016-1355-2.

Murai, K., T. W. Lehenbauer, J. D. Champagne, K. Glenn, and S. S. Aly. 2014. Cost effectiveness of diagnostic strategies using quantitative real-time PCR and bacterial culture to identify contagious mastitis cases in large dairy herds. Prev. Vet. Med. 113:522-535. https://doi.org/10.1016/j.prevetmed.2014.01.001.

Naikare, H., D. Bruno, D. Mahapatra, A. Reinisch, R. Raleigh, and R. Sprowls. 2015. Development and evaluation of a novel taqman real-time PCR assay for rapid detection of Mycoplasma bovis: Comparison of assay performance with a conventional PCR assay and another Taqman real-time PCR assay. Vet. Sci. 2:32-42. https: //doi.org/10.3390/vetsci2010032.

National Mastitis Council (NMC). 2017. Laboratory Handbook on Bovine Mastitis, 3rd ed. NMC, New Prague, MN.

Notomi, T., H. Okayama, H. Masubuchi, T. Yonekawa, K. Watanabe, N. Amino, and T. Hase. 2000. Loop-mediated isothermal amplification of DNA. Nucleic Acids Res. 28:E63.

Parikh, R., A. Mathai, S. Parikh, G. Chandra Sekhar, and R. Thomas, 2008. Understanding and using sensitivity, specificity and predictive values. Indian J. Ophthalmol. 56:45-50.

Parker, A. M., J. K. House, M. S. Hazelton, K. L. Bosward, and P. A. Sheehy. 2017. Comparison of culture and a multiplex probe PCR for identifying Mycoplasma species in bovine milk, semen and swab samples. PLoS One 12:e173422. https://doi.org/10.1371/journal pone. 0173422 .

Parker, A. M., P. A. Sheehy, M. S. Hazelton, K. L. Bosward, and J. K. House. 2018. A review of Mycoplasma diagnostics in cattle. J. Vet. Intern. Med. 32:1241-1252.

Poon, L. L., C. S. Leung, K. H. Chan, J. H. Lee, K. Y. Yuen, Y. Guan, and J. S. Peiris. 2005. Detection of human influenza A 
viruses by loop-mediated isothermal amplification. J. Clin. Microbiol. 43:427-430.

Quigley, L., O. O'Sullivan, T. P. Beresford, R. Paul Ross, G. F. Fitzgerald, and P. D. Cotter. 2012. A comparison of methods used to extract bacterial DNA from raw milk and raw milk cheese. J. Appl. Microbiol. 113:96-105. https://doi.org/10.1111/j.1365-2672 2012.05294.x.

Register, K. B., L. Thole, R. F. Rosenbush, and F. C. Minion. 2015. Multilocus sequence typing of Mycoplasma bovis reveals host-specific genotypes in cattle versus bison. Vet. Microbiol. 175:92-98. https://doi.org/10.1016/j.vetmic.2014.11.002.

Rossetti, B. C., J. Frey, and P. Pilo. 2010. Direct detection of Mycoplasma bovis in milk and tissue samples by real-time PCR. Molecular and cellular probes. Mol. Cell. Probes 24:321-323. https://doi .org/10.1016/j.mcp.2010.05.001.

Sachse, K., H. S. Salam, R. Diller, E. Schubert, B. Hoffmann, and H. Hotzel. 2010. Use of a novel real-time PCR technique to monitor and quantitate Mycoplasma bovis infection in cattle herds with mastitis and respiratory disease. Vet. J. 186:299-303. https://doi .org $/ 10.1016 /$ j.tvjl.2009.10.008

Thompson, J. D., D. G. Higgins, and T. J. Gibson. 1994. CLUSTAL W: Improving the sensitivity of progressive multiple sequence alignment through sequence weighting, position-specific gap penalties and weight matrix choice. Nucleic Acids Res. 22:4673-4680.
Tomita, N., Y. Mori, H. Kanda, and T. Notomi. 2008. Loop-mediated isothermal amplification (LAMP) of gene sequences and simple visual detection of products. Nat. Protoc. 3:877-882. https://doi .org/10.1038/nprot.2008.57.

Untergasser, A., I. Cutcutache, T. Koressaar, J. Ye, B. C. Faircloth, M. Remm, and S. G. Rozen. 2012. Primer3-new capabilities and interfaces. Nucleic Acids Res. 40:e115.

USDA. 2008. Prevalence of Contagious Mastitis Pathogens on U.S. Dairy Operations, 2007. United States Department of Agriculture, Animal and Plant Health Inspection Service, Riverdale, MD.

Wise, K. S., M. J. Calcutt, M. F. Foecking, K. Roske, R. Madupu, and B. A. Methe. 2011. Complete genome sequence of Mycoplasma bovis type strain PG45 (ATCC 25523). Infect. Immun. 79:982-983. https://doi.org/10.1128/IAI.00726-10.

World Organisation for Animal Health. 2010. Principles and methods of validation of diagnostic assays for infectious diseases. Pages 1-18 in OIE Terrestrial Manual. Vol. 19. G. A. Cullen and S. Edwards, ed. World Organisation for Animal Health (OIE), Paris, France.

Ye, J., G. Coulouris, I. Zaretskaya, I. Cutcutache, S. Rozen, and T. L. Madden. 2012. Primer-BLAST: A tool to design target-specific primers for polymerase chain reaction. BMC Bioinformatics 13:134. https://doi.org/10.1186/1471-2105-13-134. 